\title{
FRAMEWORK TEKNOLOGI MULTIMEDIA UNTUK PENGAJARAN BAHASA INGGRIS
}

\author{
Mita Nur Aflah ${ }^{1}$ Gina Selvira Yanti ${ }^{2}$ \\ ${ }^{1,2}$ Sekolah Tinggi Bahasa Asing Pontianak \\ email: mithanuraflah@gmail.com \\ email: naa.hye1831@ gmail.com
}

\begin{abstract}
Technology plays an important role in teaching and learning process. The use of technology in the classroom helps practitioners to improve the effectiveness of learning. Concerning with these facts, it is necessary to have specific guidelines regarding the implementation of technology in the classroom to optimize the benefits of the technology. This study aims to explain the notion of technology integration and its use in the classroom. It provides multimedia technology-based teaching framework contains activities that can be used by teachers or lecturers to be applied in the classroom. This study also explains some of the literature from previous researchs on the use of multimedia technology which has the role of improving students English language skills. Hopefully, this research can be useful for educators to integrate multimedia technology in the classroom.
\end{abstract}

Keywords: multimedia technology, technology integration, language teaching.

\begin{abstract}
Abstrak
Teknologi telah memainkan peran penting dalam proses belajar mengajar. Pemanfaatan teknologi di dalam maupun di luar kelas telah membantu para praktisi pendidikan untuk meningkatkan efektivitas pembelajaran. Berangkat dari fakta tersebut maka perlu adanya panduan khusus mengenai penerapan teknologi di dalam kelas guna mengoptimalkan manfaat dari teknologi tersebut. Penelitian ini bertujuan memaparkan pengertian integrasi teknologi beserta pemanfaatannya di dalam kelas. Dilengkapi pula dengan framework pengajaran berbasis teknologi multimedia yang berisikan aktivitas yang dapat digunakan para guru atau dosen untuk diterapkan di dalam kelas. Penelitian ini juga menjelaskan tentang beberapa literatur dari penelititan sebelumnya mengenai penggunaan teknologi multimedia yang telah berperan meningkatkan keterampilan Bahasa Inggris peserta didik. Harapannya, penelitian ini dapat menjadi referensi untuk para pendidik dalam mengintegrasikan teknologi multimedia di dalam kelas.
\end{abstract}

Kata kunci: teknologi multimedia, integrasi teknologi, pengajaran bahasa. 


\section{PENDAHULUAN}

Seiring dengan peningkatkan kualitas pendidikan dalam dunia yang semakin digital, teknologi sering dilihat sebagai cara untuk meningkatkan pembelajaran di kampus dan sekolah. Penggunaan teknologi telah menjadi bagian penting dari proses pembelajaran di dalam dan di luar kelas. Beberapa peneliti telah membuktikan bahwa teknologi dapat digunakan untuk membantu dan meningkatkan kemampuan bahasa mahasiswa. Seperti pendapat yang dikemukakan oleh Ahmadi (2018) teknologi memungkinkan para guru untuk merancang dan menyesuaikan kegiatan kelas sehingga dapat meningkatkan proses pembelajaran bahasa. Namun, menempatkan komputer dan perangkat lunak di ruang kelas tidaklah cukup. Yang penting untuk dipersiapkan oleh para pendidik adalah strategi atau teknik mengajar yang tepat untuk membuat penggunaan teknologi didalam kelas dapat dirasakan manfaatnya (Solano, Cabrera, Ulehlova, \& Espinoza, 2017). Saeed (2015) menunjukkan bahwa dalam mengintegrasikan teknologi, konten dan praktik pengajaran yang efektif harus menjadi hal utama yang dipertimbangkan. Fokusnya harus pada bagaimana dan mengapa teknologi digunakan. Dengan demikian, penerapan atau integrasi teknologi yang sukses dapat dilakukan dengan berfokus pada misi untuk meningkatkan keterampilan bahasa atau skills peserta didik.

Ulasan penelitian terbaru tentang pengajaran yang didukung oleh teknologi mengungkapkan adanya sejumlah poin penting. Sebagai contoh, menurut Ammade et al. (2018) mengemukakan bahwa integrasi teknologi di dalam kelas memainkan peran positif dalam menciptakan proses belajar mengajar yang berorientasi pada mahasiswa sehingga dapat membantu meningkatkan keaktifan dan proses berpikir mahasiswa. Selain itu Tinio (2016) menemukan dalam studinya bahwa integrasi teknologi memiliki manfaat untuk motivasi mahasiswa dan dapat meningkatkan kepercayaan diri mahasiswa. Selain itu integrasi teknologi juga dapat meningkatan keterlibatan mahasiswa di dalam kelas, meningkatkan dan dapat meningkatkan keterampilan dalam penggunaan teknologi (Costley, 2014). Dalam penelitian lain juga dijelaskan bahwa penerapan teknologi dalam pendidikan dapat meningkatkan keterampilan dan kemampuan kognitif mahasiswa (Cviko, McKenney, \& Voogt, 2014). Sejalan dengan penelitian diatas, dapat disimpulkan bahwa teknologi dalam dunia pendidikan telah memberikan perubahan dan pengaruh terhadap proses dan metode pengajaran yang digunakan guru dan dosen.

Aspek penting lainnya dari merancang metode pengajaran yang dianggap penting bagi banyak peneliti bahasa saat ini adalah teknik mengajar yang mempromosikan pembelajaran bahasa berbasis teknologi. Pengenalan teknologi dalam pendidikan bahasa telah menciptakan peluang baru dan besar bagi pelajar dan guru bahasa (Merzifonluoğlu \& Gonulal, 2018). Pendekatan mengajar berbasis teknologi dapat membantu guru atau dosen dalam menyelesaikan tantangan yang dihadapi oleh guru bahasa yaitu bagaimana meningkatkan minat dan motivasi mahasiswa untuk belajar (Ghavifekr \& Rosdy, 2015). Selain itu, pengajaran berbasis teknologi dapat mengembangkan kemampuan berkomunikasi mahasiswa sehingga dapat memotivasi mereka untuk lebih percaya diri dalam menggunakan bahasa yang dipelajari (Costley, 2014). Tambahan pula, mengintegrasikan teknologi dalam pengajaran Bahasa dapat memberikan peluang bagi peserta didik untuk menggunakan Bahasa secara langsung ketika berinteraksi dengan teknologi; mereka belajar kosa kata baru, mengetahui artinya dan belajar cara mengucapkannya (Mafuraga \& Moremi, 2017). Pada intinya, temuan-temuan penelitian diatas menunjukkan bahwa penggunaan pengajaran berbasis teknologi dapat meningkatkan keterampilan berbahasa peserta didik.

Berdasarkan tinjauan pustaka diatas, peneliti terinspirasi untuk melakukan pengembangan dalam teknik mengajar dengan memanfaatkan teknologi. Peneliti akan merancang framework pengajaran 
berbasis teknologi multimedia yang berisikan aktivitas yang dapat digunakan para guru atau dosen untuk diterapkan di dalam kelas. Peneliti juga menjelaskan tentang beberapa literatur dari penelititan sebelumnya mengenai penggunaan teknologi multimedia yang telah berperan meningkatkan keterampilan Bahasa Inggris peserta didik. Hasil tulisan ini diharapkan dapat digunakan untuk memfasilitasi guru atau dosen untuk dapat menerapkan strategi pengajaran Bahasa Inggris yang didukung dengan kecanggihan multimedia/teknologi.

\section{METODE PENELITIAN}

Metodologi penelitian ini mengadopsi penelitian peninjauan ruang lingkup, yang merupakan proses tinjauan pustaka antara teori dan gagasan baru. Tujuan dari penelitian peninjauan ruang lingkup adalah untuk menemukan semua materi yang terkait dengan topik tanpa adanya batasan (Arksey \& O'Malley, 2005). Metode studi pelingkupan merujuk pada identifikasi beberapa literatur yang relevan yang terlepas dari desain penelitian. Berdasarkan pendekatan tersebut, penelitian ini menganalisis dan meninjau literatur yang berkaitan dengan teknologi multimedia dalam pengajaran Bahasa Inggris. Adapun langkah pertama, peneliti memaparkan pengertian integrasi teknologi, kemudian dilanjutkan dengan melacak bukti dari penelitian sebelumnya mengenai manfaat teknologi multimedia dalam pengajaran Bahasa Inggris. Dibagian akhir dijelaskan pula framework pengajaran berbasis teknologi multimedia yang berisikan aktivitas yang dapat diaplikasikan di pengajaran Bahasa.

\section{HASIL DAN PEMBAHASAN \\ Pengertian Integrasi Teknologi di dalam Kelas}

Hampir tidak ada definisi standar yang jelas tentang integrasi teknologi, meskipun integrasi teknologi telah menjadi topik yang sangat populer di kalangan praktisi pendidikan dan peneliti. Davies and West (2013) mengungkapkan beberapa peneliti sepakat bahwa integrasi teknologi dipahami dan dilaksanakan dalam bentuk penggunaan aplikasi atau perangkat komputer di kelas, dan juga bagaimana guru menggunakan teknologi tersebut untuk melakukan kegiatan yang lebih andal dan produktif. Dengan kata lain, integrasi teknologi dapat terjadi jika guru telah terlatih atau terbiasa dalam berbagai penggunaan teknologi dan dalam penentuan aktivitas pembelajaran yang sesuai dengan teknologi yang digunakan (Solano, et al., 2017). Oleh karena itu guru dan siswa juga harus dapat secara rutin menggunakan teknologi tersebut guna mengoptimalkan kesempatan untuk berlatih dan memanfaatkan keuntungan dalam penggunaan teknologi di dalam dan di luar kelas.

Banyak pendidik dan peneliti percaya bahwa ketika upaya tanpa henti dilakukan untuk mengintegrasikan teknologi untuk pelajar bahasa asing, maka pengajaran dan pembelajaran bahasa akan berkembang dengan baik (Hamilton, 2015). Hal itu dikarenakan teknologi memiliki alat dan fitur yang akan memberi mereka peluang untuk peningkatan bahasa peserta didik (Izzah et al., 2014). Dengan penelitian yang akan datang dan kemajuan teknologi di masa depan, teknologi akan berfungsi sebagai alat bantu bagi guru bahasa untuk merancang rencana pelajaran yang lebih efektif (Summaka, Samancioglu, \& Baglibel, 2010). Selanjutnya, penelitian menunjukkan bahwa peserta didik mendapatkan manfaat pendidikan dari teknologi karena proses belajar di kelas menjadi lebih santai dan menarik (Parvin \& Salam, 2015). Teknologi nirkabel dan gadget seperti tablet dan smart phone harus dieksplorasi lebih lanjut untuk menemukan potensi media tersebut dalam pembelajaran bahasa. Dengan demikian, partisipasi aktif dari guru atau instruktur bahasa sangat penting untuk memastikan bahwa teknologi yang ada dapat sepenuhnya digunakan untuk kepentingan peserta didik ESL (Yang \& Chun, 2018).

Sementara implementasi dan penggunaan teknologi di bidang pendidikan meningkat, tolak ukur untuk penggunaan teknologi dalam pendidikan akan semakin penting. Pengambil keputusan (administrator sekolah, pemimpin pendidikan, pemerintah, otoritas lokal) 
perlu mengetahui hal ini untuk membuat keputusan yang lebih baik, menentukan kebutuhan pengembangan profesional pendidik, dan memastikan penggunaan teknologi di sekolah secara efektif dan efisien (Smaldino, Lowther, \& Mims, 2019). Jika sekolah dan guru tidak memiliki komputer yang memadai dan koneksi internet yang baik, penerapan teknologi dalam pendidikan akan sulit terwujud. Oleh karena itu integrasi teknologi dapat dimulai dengan memperkenalkan teknologi melalui pelatihan-pelatihan

profesional yang efektif.

\section{Manfaat Multimedia Teknologi Dalam Pengajaran Bahasa Inggris}

Perangkat lunak untuk pengajaran dan pembelajaran bahasa yang dibantu oleh komputer (CALL) telah menjadi media ajar untuk pengajaran bahasa kedua atau bahasa asing. Banyak peneliti telah membuktikan bahwa penggunaan komputer di kelas bahasa Inggris telah mendatangkan banyak bermanfaat bagi guru dan peserta didik. Menurut Merzifonluoğlu \& Gonulal (2018) implementasi teknologi dalam pendidikan untuk English Foreign Learners telah menciptakan inovasi bagi pelajar dan guru bahasa. Mereka setuju bahwa teknologi telah mengubah perspektif untuk mengajar dan belajar bahasa Inggris dan mereka percaya bahwa teknologi telah membantu pelajar dan guru untuk meningkatkan pengajaran bahasa Inggris (Merzifonluoğlu \& Gonulal, 2018). Sejalan dengan penelitian diatas, dapat disimpulkan bahwa teknologi dalam dunia pendidikan telah memberikan perubahan dan pengaruh terhadap proses dan metode pengajaran yang digunakan guru (Ahmad \& Nisa, 2016).

Dalam penelitian lainnya, pengajaran bahasa asing berbasis teknologi telah memberikan banyak strategi yang efektif dalam proses pembelajaran (Motteram, 2013). Penggunaan teknologi dalam pengajaran telah memberikan peluang bagi peserta didik untuk meningkatkan keterampilan bahasa asing mereka melalui teknologi (Altun, 2015). Shyamlee (2012) juga telah menganalisis perlunya menggunakan teknologi multimedia untuk pengajaran bahasa. Analisis tersebut menunjukkan bahwa menggunakan teknologi multimedia memiliki fitur untuk meningkatkan motivasi dan perhatian belajar siswa (Shyamlee, 2012). Hal ini bertujuan untuk melibatkan siswa dalam proses pembelajaran bahasa melalui komunikasi satu sama lain. Pada penelitian lain Reinders (2012) juga merekomendasikan penggunaan teknologi multimedia di ruang kelas karena efek positifnya pada proses pengajaran tanpa mengabaikan peran efektif guru. Dengan kata lain, lingkungan belajar dengan dukungan teknologi dapat memotivasi peserta didik untuk mencapai kompetensi yang lebih baik.

Selain penelitian di atas, studi lain yang dilakukan oleh Nomass (2013) menunjukkan peran pendekatan teknologi modern dalam mengajar bahasa Inggris sebagai bahasa kedua, dan kelemahan dari pendekatan pengajaran konvensional. Dalam penelitian tersebut peneliti fokus menggunakan situs web pembelajaran, program komputer, perangkat lunak presentasi, kamus elektronik, chatting dan email, CD, dan klip video (Nomass, 2013). Saat ini, ada banyak program aplikasi perangkat lunak yang tersedia seperti program pembelajaran kosa kata, tata bahasa dan pelafalan, utilitas pemeriksaan ejaan, buku kerja elektronik, program membaca dan menulis, dan paket pembelajaran yang berbeda untuk membantu instruktur atau guru dalam membuat latihan tutorial untuk meningkatkan bahasa Inggris mereka. Dengan demikian guru, dosen dan instruktur pendidikan dapat menggunakan berbagai macam aplikasi atau teknologi multimedia yang sesuai untuk di integrasikan di dalam kelas. Oleh karena itu, seiring dengan perkembangan teknologi seyogianya akan muncul lebih banyak metode pengajaran yang inovatif dan dapat meningkatkan minat belajar siswa.

\section{Framework Pengajaran Berbasis Teknologi Multimedia}

Kemampuan para guru untuk mengintegrasikan teknologi ke dalam metode pengajaran yang berbeda menjadi 
hal penting dikarenakan kemajuan pesat teknologi di abad kedua puluh satu (Tanak, 2018). Namun, tidak semua jenis teknologi efektif untuk meningkatkan proses pendidikan. Agar sejalan dengan perkembangan teknologi yang melibatkan partisipasi para siswa yang merupakan warga digital asli, diperlukan tingkat pemahaman yang baik oleh para guru dan dosen (Yuyun, 2018). Dengan demikian, pendidik harus cukup berpengalaman untuk mengetahui cara membedakan antara program yang berbeda, dan memilih aplikasi atau program yang mana yang paling cocok dengan peserta didik. Sama seperti proyek apa pun, integrasi teknologi dalam pendidikan memerlukan rencana implementasi. Berdasarkan hal tersebut, makalah ini bertujuan untuk menyoroti peran menggunakan teknologi modern dalam mengajar bahasa Inggris sebagai bahasa kedua. Pada bagian ini akan dipaparkan framework pengajaran yang dapat digunakan para guru dan dosen bahasa Inggris untuk meningkatkan keterampilan belajar peserta didik dengan menggunakan teknologi. Di antara teknikteknik yang akan digunakan adalah situs web pembelajaran bahasa Inggris online, program pembelajaran bahasa berbantuan komputer, perangkat lunak presentasi, kamus elektronik, program chatting dan pesan email, dan belajar klip video.

\section{Tahap Pertama}

Teknologi yang di gunakan adalah laptop yang berisikan rekamam suara dari penutur asing dalam bentuk percakapan atau ceramah dan sound system (speaker). 1) Dosen melakukan brainstorming topik dari materi yang akan di pelajari dan menekankan pada frasa dan kosa kata penting, 2) Setelah itu Dosen meminta mahasiswa untuk melengkapi kalimat atau frasa pagi bagian yang masih kosong pada lembar yang berisi rekaman yang mereka dengarkan., 3) Dosen meminta mahasiswa untuk melakukan kegiatan meniru secara berpasangan. Mereka mendengarkan rekaman dan memperhatikan cara pengucapan dan intonasi dari pembicara (penutur asli) dan kemudian berlatih untuk berusaha menyamai si penutur asli.

\section{Tahap Kedua}

Teknologi yang di gunakan adalah laptop yang berisikan video, computer games, computer application, sebagai bahan yang akan mahasiswa gunakan untuk melaksanakan tugas, 1) Dosen menjelasakan instruksi dari tugas yang akan mereka lakukan, 2) Dosen meminta mahasiswa untuk mempersiapkan presentasi dan laporan tertulis dari tugas tersebut. Dosen juga akan memonitor aktivitas mahasiswa ketika melakukan tugas, 3) Dosen meminta mahasiswa untuk mempresentasikan hasil tugas mereka, 4) Mereka akan mendapatkan feedback atau masukan dari dosen setelah melakukan presentasi.

\section{$\underline{\text { Tahap Ketiga }}$}

Diskusi, umpan balik dan tinjauan akhir, 1) Dosen mefasilitasi mahasiswa untuk berdiskusi dan bersama-sama menganalisa hasi kerja mereka, 2) Mahasiswa bersama-sama mengidentifikasi dan menganalisa fokus bahasa yang terdapat pada hasil tugas mereka, 3) Sebagai tinjauan akhir, mahasiswa melakukan tugas yang berkaitan tentang materi ajar dan mereka juga harus melaporkan hasil kerja mereka di depan kelas.

Berdasarkan framework di atas, dapat disimpulkan bahwa jika digunakan dengan benar oleh guru atau dosen maka teknologi dapat memiliki potensi untuk menjadikan pengajaran lebih mudah, lebih menantang dan dapat memotivasi guru atau dosen dalam merancang teknik mengajar kekinian yang efektif.

\section{SIMPULAN}

Dengan adanya kemajuan teknologi, pengajaran bahasa mulai lebih menekankan pada interaksi yang komunikatif dan otentik. Adanya petunjuk atau rancangan pembelajaran yang jelas dalam mengintegrasikan teknologi di dalam kelas dapat menjadikan proses belajar mengajar lebih efektif. Jika teknologi terintegrasi secara efektif, maka dapat memberikan peserta didik peluang besar untuk meningkatkan keterampilan berbahasa mereka. 


\section{UCAPAN TERIMA KASIH}

Penulis mengucapkan terima kasih kepada Direktorat Jenderal Penguatan Riset dan Pengabdian Masyarakat, Kementrian Riset, Teknologi, dan Pendidikan Tinggi, dan kepada LPPM STBA beserta pihak akdemik di Sekolah Tinggi Bahasa Asing Pontianak atas bantuan dan dukungan yang diberikan dalam penelitian ini.

\section{DAFTAR RUJUKAN}

Ahmad, R., \& Nisa, M. U. (2016). The Significance of Educational Technology in Teaching Learning process. The International Journal of Indian Psychology, 4(1).

Ahmadi, M. R. (2018). The Use of Technology in English Language Learning: A Literature Review. International Journal of Research in English Education (IJREE), 3(2).

Altun, M. (2015). The Integration Of Technology Into Foreign Language Teaching International Journal on New Trends in Education and Their Implications, Vol. 6(1).

Ammade, S., Mahmud, M., Jabu, B., \& Tahmir, S. (2018). Integrating Technology in English Language Teaching: Global Experiences and Lessons for Indonesia. International Journal of English Linguistics, Vol. 8(No. 6).

Arksey, H., \& O'Malley, L. (2005). Scoping studies: towards a methodological framework International Journal of Social Research Methodology, Vol. 8(1), 19-32. doi: DOI:10.1080/1364557032000119616

Costley, K. C. (2014). The Positive Effects of Technology on Teaching and Student Learning. Arkansas Tech University. Arkansas

Cviko, A., McKenney, S., \& Voogt, J. (2014). Teacher roles in designing technology-rich learning activities for early literacy: A cross-case analysis. Elsevier-Computers \& Education 72, 68-79.

Davies, R. S., \& West, R. E. (2013). Technology Integration in Schools Handbook of Research on
Educational Communications and Technology

Ghavifekr, S., \& Rosdy, W. A. W. (2015). Teaching and Learning with Technology: Effectiveness of ICT Integration in Schools. International Journal of Research in Education and Science (IJRES), 1(2), 175-191.

Hamilton, B. (2015). Integrating Technology in the Classroom P. Wurster (Ed.) Tools to Meet the Needs of Every Student

Izzah, H. N., Mansor, N., Ibrahim, S. H., Ahmad, N. M., Salam, W. N. W., \& Mamat, M. Z. (2014). Integrating Communicative Approach and Technology in Esl Classroom Journal of Business and Social Development Vol. 2(1), 30-36.

Mafuraga, M., \& Moremi, M. (2017). Integrating Information and Communication Technology in English Language teaching: A case study of selected Junior Secondary Schools in Botswana. International Journal of Education and Development using Information and Communication Technology, Vol. 13(1), 142-152.

Merzifonluoğlu, A., \& Gonulal, T. (2018). Review of Digital language learning and teaching: Research, Theory, and Practice. Language Learning \& Technology, Vol. 22(1), 65-68.

Motteram, G. (2013). Innovations in learning technologies for English language teaching

Nomass, B. B. (2013). The Impact of Using Technology in Teaching English as a Second Language. English Language and Literature Studies, Vol. 3(1).

Parvin, R. H., \& Salam, S. F. (2015). The Effectiveness of Using Technology in English Language Classrooms. Forum for International Research in Education, 2(1).

Reinders, H. (2012). Digital games in language learning and teaching. Basingstoke: Palgrave MacMillan.

Saeed, Y. B. M. (2015). The Effect of Using Computer Technology on English Language Teachers' 
Performance. SUST Journal of Humanities, 16(1).

Shyamlee, S. D. (2012). Use of Technology in English Language Teaching and Learning. International Conference on Language, Medias and Culture, 33.

Smaldino, S. E., Lowther, D. L., \& Mims, C. (2019). Instructional Technology and Media for Learning. United States of America: Pearson Education.

Solano, L., Cabrera, P., Ulehlova, E., \& Espinoza, V. (2017). Exploring The Use Of Educational Technology In Efl Teaching: A Case Study Of Primary Education In The South Region Of Ecuador. Journal of Teaching English with Technology, Vol. 17(2), 77-86.

Summaka, M. S., Samancioglu, M., \& Baglibel, M. (2010). Technology integration and assesment in educational settings. Procedia Social and Behavioral Sciences, 2, 17251729.
Tanak, A. (2018). Designing TPACK-based course for preparing student teachers to teach science with technological pedagogical content knowledge. Kasetsart Journal of Social Sciences. doi:

https://doi.org/10.1016/j.kjss.2018.07 .012

Tinio, V. L. (2016). ICT in Education. New York: E-Primers www.eprimers.org.

Yang, G., \& Chun, L. (2018). Technology Integration into the Language Classroom: Developmental Trajectory of Beginning Teachers. Front Education China, Vol. 13(1).

Yuyun, I. (2018). Curriculum and Technology Design: A Course to Explore Technology Applications in EFL Curriculum Design. Journal of ELT Research, Vol. 3(1). 
68 JURNAL PENDIDIKAN EDUTAMA, Vol.6., No.2 Juli 2019 